\title{
Using an error-correction model to test whether endogenous long-run growth exists
}

\author{
by \\ Sau-Him Paul Lau \\ University of Hong Kong
}

January 2003

\begin{abstract}
:
A major empirical interest in growth studies is whether permanent changes in economic fundamentals affect the long-run growth rate. However, a direct time series analysis of this hypothesis may not always be feasible because the permanence of many such changes is rather questionable. This paper explains why examining the long-run effects of temporary changes in investment share on per capita output provides indirectly the answer regarding the effects of (possibly hypothetical) permanent changes in investment share, when per capita output and per capita investment are cointegrated. Applying the proposed method to the postwar data of major industrial countries, it is found that a disturbance to investment share does not produce a positive long-run effect in France, Japan and the UK. The evidence is unfavorable to the class of endogenous growth models.
\end{abstract}

JEL Classification Numbers: O40; E22

Keywords: error-correction model; presence or absence of endogenous growth

\section{Correspondence to:}

S.-H. P. Lau, School of Economics and Finance, University of Hong Kong, Pokfulam Road, Hong Kong

$\begin{array}{ll}\text { Phone: } & \text { (852) } 28578509 \\ \text { Fax: } & \text { (852) } 25481152 \\ \text { E-mail: } & \text { laushp@ @kucc.hku.hk }\end{array}$

I am grateful to Trevor Breusch, David Harris, John Hutton, Chung-Ming Kuan, Jin-Lung Lin, Nilss Olekalns, Peter Pedroni, Tony Phipps, Bill Russell, Chor-Yiu Sin, the seminar/conference participants at Academia Sinica, Australian Macroeconomics Workshop, Econometric Society Meetings, Hong Kong University of Science and Technology, McGill University, Monash University, National Taiwan University, Reserve Bank of Australia, Sydney University, Universidad de Guanajuato, University of Hawaii, University of Hong Kong, University of Melbourne, University of New South Wales, and Victoria University of Wellington for helpful comments and discussions. I am also thankful to the Australian Research Council for financial support. 


\section{Introduction}

Whether a permanent change in economic fundamentals produces a change in the long-run growth rate of the economy is an empirical question that many economists and policy makers are interested in. Moreover, it is a distinguishing characteristic between endogenous and exogenous growth models because the change leads to a growth effect (i.e., a change in the long-run growth rate) in the former class of models but only a level effect in the latter; see, for example, Romer (1986) and Lucas (1988). Based on this implication, Jones (1995) performs empirical analysis and concludes that the evidence on major industrial countries is unfavorable to the class of endogenous growth models. Similarly, Stokey and Rebelo (1995) conclude that income taxes do not have a growth effect according to the evidence provided by the tax reform 'experiment' in the USA: income tax revenues increased dramatically from $2 \%$ to $15 \%$ of output in the early 1940s, but there was no change in per capita output growth.

While the endogenous and exogenous growth models imply different long-run effects of permanent changes in economic fundamentals, a direct examination of this hypothesis may not always be feasible because the permanence of many such changes is rather questionable. As an example, one of the frequently cited evidence against endogenous growth models is that the growth rates of per capita output (in USA and other OECD countries after World War II) are essentially trendless, but many investment share (i.e., investment-output ratio) series, based on total investment or producer durables investment, contain either strong positive trends or unit roots (Jones, 1995, Table IV). While the evidence regarding stationary output growth is expected, the conclusion of non-stationary investment shares in many industrial countries is quite different from those in several well-known empirical studies such as King et al. (1991). Moreover, the stationarity of some 'great ratios' such as the consumptionoutput ratio and investment-output ratio is regarded by many researchers as a stylized fact; see King et al. (1991) and especially Cochrane (1994). One may expect that many economists and econometricians, trained to be critical and skeptical, would demand more evidence before deciding whether the endogenous growth models are empirically relevant or not.

By assuming explicitly that a permanent change in investment share is absent (or at least cannot be established affirmatively) in the data, this paper takes a complementary approach to deal with the question regarding the presence or absence of a growth effect of a (possibly hypothetical) permanent change. It examines the long-run effect of a temporary change in investment share on per capita output, and explains why the proposed method provides indirectly the answer to the above question, when per capita output and per capita investment are cointegrated. 
The connection between these two apparently distinct questions (long-run effects of permanent and temporary changes in investment share respectively) is implied by the theoretical results on the time series properties of stochastic endogenous and exogenous growth models. Lau (1997) shows that permanent changes in economic fundamentals lead to growth effects, and temporary changes cause permanent level effects for endogenous growth models. On the other hand, permanent changes in economic fundamentals lead only to level effects, and temporary changes may cause either permanent or temporary level effects for exogenous growth models. ${ }^{1}$ Moreover, Lau (1999, p. 18) points out a systematic difference between endogenous and exogenous growth models in terms of the long-run effect of a temporary change in economic fundamentals when the observed variables are cointegrated. Specifically, for a system of $n$ variables with $r(1 \leq r \leq n-1)$ cointegrating vectors, the long-run multiplier matrix for the structural vector moving-average (VMA) representation, which summarizes the long-run effects of the structural disturbances on the level of observed variables, is of reduced rank of $n-r$. If this cointegrated system is generated by an exogenous growth model, then exactly $r$ columns of the structural long-run multiplier matrix are zero. On the other hand, if this cointegrated system is generated by an endogenous growth model, then there is no column of zero in the structural long-run multiplier matrix. ${ }^{2}$

This paper exploits the above systematic difference between endogenous and exogenous growth models and examines the long-run effect of a disturbance to investment share on per capita output. An important paper, Levine and Renelt (1992), examines the results of cross-section growth studies (such as Barro, 1991; Mankiw et al., 1992) and finds that most 'statistically significant' regression results are fragile with respect to minor changes in specification. However, they do identify a positive and robust correlation between economic

\footnotetext{
$\overline{1}$ Kocherlakota and Yi (1996, p. 132) mention that "In exogenous growth models temporary policy changes do not permanently affect GNP, while in endogenous growth models temporary policy changes can permanently affect GNP." As made clear in Eq. (21) of Lau (1997), a temporary change in economic fundamentals in exogenous growth models may produce either temporary effect [if the associated external impulse process is $\mathrm{I}(0)$ ] or permanent effect [if the associated external impulse process is I(1)] on the level of output.

2 In essence, a 'reduced rank of $n-r$ (i.e., $n-r$ independent columns) in the structural long-run multiplier matrix' and ' $r$ columns of zero in this matrix' are not necessarily the same. The first condition is related to the number of independent cointegrating relationships, while the second condition is related to the zero long-run effect of some structural disturbances. The first condition only implies that at most $r$ structural disturbances produce zero long-run effect; it does not pin down the precise number of structural disturbances that produce zero long-run effect. However, this paper shows that testable implications appear when the cointegration feature is combined with the time series properties of stochastic endogenous and exogenous growth models.
} 
growth and the share of investment in output. It is interesting to investigate whether this relationship is found using time series analysis. ${ }^{3}$

Since the long-run effects of temporary changes in investment share on per capita output for endogenous and exogenous growth models have testable implications when per capita output and per capita investment are cointegrated, the empirical method proposed in this paper is designed for a bivariate cointegrated system. The procedure is then applied to post-war data of several major industrial countries. It is found that a temporary change in investment share does not produce a positive long-run effect on per capita output in France, Japan and the UK. The conclusions based on the time series studies of this paper, as well as those of Jones (1995), are quite different from the positive and significant relationship between investment share and output growth found in cross-section studies.

This paper is organized as follows. Section 2 summarizes the different properties of endogenous and exogenous growth models regarding the long-run effects of permanent and temporary changes in economic fundamentals respectively. Starting with the systematic difference between endogenous and exogenous growth models about the long-run multiplier matrix of the structural VMA representation (which summarizes the long-run effects of the underlying disturbances) when per capita output and per capita investment are cointegrated, Section 3 suggests a method to investigate whether a disturbance to investment share produces zero or positive long-run effect. Section 4 presents the empirical results. Section 5 relates the analysis of this paper to the growth literature and provides the conclusions.

\section{Long-run effects of permanent and temporary changes in eco- nomic fundamentals}

The long-run effects of permanent and temporary changes in economic fundamentals for stochastic endogenous and exogenous growth models have been examined in Lau $(1997,1999)$. To illustrate the relevant idea of these two papers in a framework which is useful to the subsequent empirical analysis, this section studies, respectively, the stochastic Solow-Swan model (Solow, 1956;

\footnotetext{
3 While different factors such as human capital, trade, government investment and tax rates have been emphasized in the growth literature (such as Lucas, 1988; Glomm and Ravikumar, 1994; Collard, 1999), the one variable which is present in most, if not all, growth models is investment in physical capital. Jones (1995, p. 505) suggests that a test based on investment data may, arguably, be regarded as providing evidence with respect to the endogenous versus exogenous growth debate for the whole class of growth models, rather than for a specific model only.
} 
Swan, 1956) and its endogenous growth counterpart.

Consider first a stochastic version of the Solow-Swan model with exogenous technological progress. A closed economy is populated by a constant number (equal to labor input, $N$ ) of identical agents. The supply side of the economy is characterized by the following Cobb-Douglas production function of a representative agent,

$$
Y_{t}=A K_{t}^{\alpha}\left[(1+\tau)^{t} N\right]^{1-\alpha} e_{t}^{P}
$$

where $0<\alpha<1, \tau>0, Y_{t}$ is output at time $t, K_{t}$ is capital input at $t$, and $e_{t}^{P}$ is an impulse process to productivity. Parameter $\tau$ is the average rate of exogenous labor-augmenting technological progress.

The demand side of the economy is represented by:

$$
\frac{I_{t}}{Y_{t}}=s e_{t}^{I}
$$

where $I_{t}$ is investment at time $t, s(0<s<1)$ is the average investment share in output, and $e_{t}^{I}$ is an external impulse to the investment share at time $t$. Capital stock is assumed to depreciate at a constant rate of $\delta(0<\delta<1)$ per period.

The two mean-zero external impulse processes are assumed to have the following form:

$$
(1-L)^{c_{j}} q_{j}(L) \ln e_{t}^{j}=\varepsilon_{t}^{j},
$$

where $j=P$ or $I, L$ is the lag operator $\left(L \ln e_{t}^{j}=\ln e_{t-1}^{j}\right)$, parameter $c_{j}$ is either 0 or $1, q_{j}(L)$ contains only roots strictly outside the unit circle, and $\varepsilon_{t}^{P}$ and $\varepsilon_{t}^{I}$ are uncorrelated white noise structural disturbances. ${ }^{4}$ The impulse process $\ln e_{t}^{j}$ is $\mathrm{I}(0)$ when $c_{j}=0$ or is $\mathrm{I}(1)$ without drift when $c_{j}=1$.

Denote in lower case letter the corresponding variable per capita. In order for log per capita output and log per capita investment to be difference-stationary and cointegrated in this model, it can be shown that one impulse process should be I(1) and the other I(0); see, for example, Section 5.1 of Lau (1997). Assuming that the productivity and investment share impulses are I(1) without drift and $\mathrm{I}(0)$ respectively, then $c_{P}=1$ and $c_{I}=0$ in Eq. (3). In this case, the log-linearized equations of motion near the steady-state growth path have

4 The distinction of the two terms 'external impulse' $\left(\ln e_{t}^{j}\right)$ and 'structural disturbance' $\left(\varepsilon_{t}^{j}\right)$, which are related by Eq. (3), is maintained throughout the analysis. Specifically, while a structural disturbance process is restricted to be white noise, an external impulse process may be I(0) or I(1). Nevertheless, a structural disturbance may produce temporary or permanent effects, depending on other aspects of the growth model. 
the following VMA form:

$$
\begin{aligned}
& {\left[\begin{array}{c}
(1-L) \ln y_{t} \\
(1-L) \ln i_{t}
\end{array}\right]=\left[\begin{array}{l}
\tau \\
\tau
\end{array}\right]+\left(1-\frac{(1+\tau)-(1-\alpha)(\tau+\delta)}{1+\tau} L\right)^{-1}} \\
& \times\left[\begin{array}{ll}
\left(1-\frac{1-\delta}{1+\tau} L\right) q_{P}^{-1}(L) & (1-L) \frac{\alpha(\tau+\delta)}{1+\tau} L q_{I}^{-1}(L) \\
\left(1-\frac{1-\delta}{1+\tau} L\right) q_{P}^{-1}(L)(1-L)\left(1-\frac{1-\delta}{1+\tau} L\right) q_{I}^{-1}(L)
\end{array}\right]\left[\begin{array}{c}
\varepsilon_{t}^{P} \\
\varepsilon_{t}^{I}
\end{array}\right] .
\end{aligned}
$$

(All detailed derivations are contained in an Appendix available from the author upon request.)

It can be observed that the long-run growth rate in this model is affected by the rate of technological progress only. The long-run effects on output and investment level of a disturbance to productivity and investment share, respectively, will be discussed later.

The simplest way to 'endogenize' the source of growth is the AK model (Rebelo, 1991). The (exogenous investment-share version of) stochastic AK model consists of Eqs. (2), (3) and

$$
Y_{t}=A K_{t} e_{t}^{P}
$$

It can be shown that if the order of integration of log per capita output or log per capita investment is at most one, then both external impulses should be $\mathrm{I}(0)$ in this model, i.e., $c_{P}=c_{I}=0$ in Eq. (3). See, for example, Section 5.2 of Lau (1997).

In this case, the log-linearized equations of motion near the steady-state growth path have the following VMA representation:

$$
\begin{gathered}
{\left[\begin{array}{c}
(1-L) \ln y_{t} \\
(1-L) \ln i_{t}
\end{array}\right]=\left[\begin{array}{l}
\ln (1-\delta+s A) \\
\ln (1-\delta+s A)
\end{array}\right]} \\
+\left[\begin{array}{cc}
\left(1-\frac{1-\delta}{1-\delta+s A} L\right) q_{P}^{-1}(L) & \frac{s A}{1-\delta+s A} L q_{I}^{-1}(L) \\
\left(1-\frac{1-\delta}{1-\delta+s A} L\right) q_{P}^{-1}(L) & \left(1-\frac{1-\delta}{1-\delta+s A} L\right) q_{I}^{-1}(L)
\end{array}\right]\left[\begin{array}{c}
\varepsilon_{t}^{P} \\
\varepsilon_{t}^{I}
\end{array}\right] .
\end{gathered}
$$

It is easy to observe from Eq. (6) that a permanent change in the investment share (represented by a change in parameter $s$ ) will produce growth effects on both output and investment.

The above analysis shows that both Eq. (4) of the Solow-Swan model and Eq. (6) of the AK model can be represented by the following first-difference VMA 
form: ${ }^{5}$

$$
\left[\begin{array}{c}
\Delta x_{1 t} \\
\Delta x_{2 t}
\end{array}\right]=\text { constant }+M(L) \varepsilon_{t} \equiv \text { constant }+\left[\begin{array}{cc}
M_{11}(L) & M_{12}(L) \\
M_{21}(L) & M_{22}(L)
\end{array}\right] \varepsilon_{t},
$$

where $\Delta \equiv 1-L$ is the first-difference operator, $x_{1}$ and $x_{2}$ stand for the log of per capita output and the log of per capita investment respectively, $\varepsilon_{t}=$ $\left(\varepsilon_{1 t}, \varepsilon_{2 t}\right)^{\prime}$ is a $2 \times 1$ vector of structural disturbances such that its components are serially and mutually uncorrelated, the $2 \times 2$ matrix of lag polynomial $M(L)$ is defined by $M(L)=\sum_{j=0}^{\infty} M_{j} L^{j}$, and the 'constant' vector is nonzero (in order for the variables to demonstrate long-run growth). How this 'constant' vector is related to the behavioral parameters is important to the long-run effects of permanent changes in these parameters, as illustrated in the above analysis and in Section 4 of Lau (1997). Other than this issue, its precise value is inconsequential to the analysis and therefore is left unspecified.

Following the terminology in the vector autoregression (VAR) literature, the time-invariant system (7) is called the structural model. Since these relationships are structural, the off-diagonal elements of the leading VMA parameter matrix $M_{0}$ may be non-zero; see, for example, Eqs. (4) and (6). For a meaningful structural model, the inverse of $M_{0}$ exists. Note that the variancecovariance matrix of the structural disturbances $\varepsilon_{t}$ is a diagonal matrix. Moreover, the two variances can be normalized to be one without loss of generality. The long-run multiplier matrix of the structural VMA representation (7) is given by

$$
M(1)=\sum_{j=0}^{\infty} M_{j}
$$

and its various elements contain information about the long-run effects of structural disturbances on the level of observed variables.

It can be observed from Eq. (4) that the long-run multiplier matrix of the stochastic Solow-Swan model is given by:

$$
M(1)=\left[\begin{array}{lll}
\frac{\tau+\delta}{1+\tau} q_{P}^{-1} & (1) & 0 \\
\frac{\tau+\delta}{1+\tau} q_{P}^{-1} & (1) & 0
\end{array}\right]
$$

The first column of the long-run multiplier matrix in Eq. (4a) is non-zero and the second column is zero, reflecting that a productivity disturbance produces permanent effects and a disturbance to investment share produces temporary

\footnotetext{
5 More generally, the structural VMA representation of an exogenous growth model and an endogenous growth model are given respectively by Eqs. (21) and (14) of Lau (1997). Both equations can be represented by a multivariate generalization of Eq. (7) of this paper.
} 
effects. On the other hand, the long-run multiplier matrix of the stochastic AK model is given by:

$$
M(1)=\left[\begin{array}{l}
\frac{s A}{1-\delta+s A} q_{P}^{-1}(1) \frac{s A}{1-\delta+s A} q_{I}^{-1}(1) \\
\frac{s A}{1-\delta+s A} q_{P}^{-1}(1) \frac{s A}{1-\delta+s A} q_{I}^{-1}(1)
\end{array}\right] .
$$

Both columns of the long-run multiplier matrix in Eq. (6a) are non-zero, reflecting that the effect of either a disturbance to productivity or investment share is permanent. It can be observed from (4a) and (6a) that the $2 \times 2$ long-run multiplier matrix $M(1)$ of both models are of reduced rank of one, meaning that per capita output and per capita investment are cointegrated.

The above analysis shows that if the cointegrated system (7) is generated by an endogenous growth model, then both external impulses are I(0) but each of them produces non-zero long-run effects and therefore both columns of $M(1)$ are non-zero; see Eqs. (6) and (6a). ${ }^{6}$ Moreover, in a cointegrated system of per capita output and per capita investment, a positive disturbance to productivity (respectively investment share), which increases current per capita output (respectively per capita investment), is expected to produce positive (instead of negative) long-run effects on either variable for a meaningful endogenous growth model. Therefore, both columns of $M(1)$ are positive. On the other hand, if the cointegrated system (7) is generated by an exogenous growth model, then one external impulse process is $\mathrm{I}(0)$ and the other is $\mathrm{I}(1)$. As I(0) impulses produce only temporary effects for exogenous growth model, one column of the long-run multiplier matrix $M(1)$ will be zero; see Eqs. (4) and $(4 \mathrm{a}) .^{7}$

In summary, the long-run effects of permanent and temporary changes in economic fundamentals differ for endogenous and exogenous growth models. Moreover, the long-run effects of permanent and temporary changes are related as each is caused by the presence or absence of the factor $(1-L)$ in the determinant of the polynomial matrix of the behavioral systems; see, for example, Eqs. (37) and (32) of Lau (1997). The difference of the long-run effects of permanent changes in economic fundamentals between these two classes of models is a very sharp distinction: a permanent change in some behavioral parameters (such as the average investment share $s$ ) will lead to a

$\overline{6}$ To be exact, the endogenous growth literature only suggests that these longrun effects are not necessarily zero. In principle, any column of $M(1)$ may still be arbitrarily close to zero. However, this probability zero event is ignored in this paper.

7 If both impulses are I(1), then no column of $M(1)$ is zero and the system is not cointegrated. Therefore, the systematic difference between endogenous and exogenous growth models regarding the long-run effects of structural disturbances disappears for an I(1) but non-cointegrated system. 
growth effect for an endogenous growth model, whereas a permanent change in the underlying parameters, other than the exogenous rate of technological progress, leads only to a level effect for an exogenous growth model. Unfortunately, this implication may not be testable as it is difficult to find interesting events of permanent changes in behavioral parameters.

On the other hand, temporary changes in economic fundamentals are easier to find. Regarding the long-run effects of these temporary changes, there is also a systematic difference between these two classes of models when the variables are cointegrated. From the next section onwards, the difference for the longrun effects of temporary changes between endogenous and exogenous growth models will be exploited to develop a testing procedure, and the focus will be on the long-run multiplier matrix for the structural VMA representation (7) of a cointegrated system. As the above analysis makes clear, testing the long-run effect of a temporary change in economic fundamentals provides an indirect answer regarding the effect of a permanent change.

\section{Investigating the long-run effect of a disturbance to investment share}

The analysis of Section 2 shows that for a bivariate cointegrated system of per capita output and per capita investment, both columns of the long-run multiplier matrix $M(1)$ in Eq. (7) are positive if the data are generated by an endogenous growth model, but one column of $M(1)$ is positive and the other is zero if the data are generated by an exogenous growth model. Provided that the structural model is identified, this is a testable hypothesis.

This section elaborates the above idea and suggests a simple method to examine whether the long-run effect of an investment share disturbance on per capita output is zero or positive. Specifically, Sub-section 3.1 discusses how identification is achieved in this paper. Under the particular identifying assumption, Sub-section 3.2 then suggests a simple way to test the hypothesis that an investment share disturbance produces a zero long-run effect. Combining all the results, Sub-section 3.3 summarizes the empirical procedure used in this paper. Before that, the next paragraph discusses the validity of the implicit assumption made in this paper that productivity disturbances always produce permanent effects.

When per capita output and per capita investment are cointegrated (and thus the rank of $M(1)$ in Eq. (7) is one), at least one structural disturbance always produces permanent effects. It is assumed in this paper that the productivity disturbance always produces a permanent effect but the investment share disturbance may produce a temporary or permanent effect. In the notation of 
this paper, the first column of $M(1)$ is non-zero but the second column may be zero or non-zero. This specification is justified on two grounds. First, such a specification is flexible to allow the data to decide whether a disturbance to investment share produces a temporary effect or not, which is the main objective of this paper. Changing the roles of the two structural disturbances just presupposes the answer. Second, if the investment share disturbance is interpreted according to Eqs. (2) and (3), then the above assumptions regarding the roles of the two structural disturbances is equivalent to assuming that the external impulse to the investment share is $\mathrm{I}(0)$. In this case, $c_{I}=0$ in Eq. (3) and the investment-output ratio is stationary, which is consistent with the empirical evidence on industrial countries; see, for example, King et al. (1991).

\subsection{Identifying assumptions}

Regarding the assumptions used to identify the structural model, this paper makes use of the idea in the theoretical growth literature that current output is determined in the supply side by factor inputs such as capital and labor. Specifically, it is assumed in many growth models that current output is determined in the supply side according to the production function, as illustrated in Eq. (1) of the Solow-Swan model or Eq. (5) of the AK model. On the other hand, the decision between current consumption and investment for future capital is made on the basis of some demand-side or preference factors, such as the simple investment rule used in the Solow-Swan model or a more complicated mechanism based on optimizing an intertemporal objective function. As a result, variables (such as investment) which are not present in the production function do not affect current output but may still affect future output through, for example, capital accumulation.

When the idea of supply-side determination of current output is interpreted in a stochastic setting, it implies a recursive nature regarding the structural disturbances. Only disturbances affecting the production technology $\left(\varepsilon_{t}^{P}\right.$ in the models of Section 2) or the inputs will affect output contemporaneously, whereas other variables such as investment are contemporaneously affected by all disturbances. (Figures 4.9 and 4.10 in Mankiw (1997) and the assumptions used in Kocherlakota and Yi (1996, footnote 4) also reflect the supply-side determination of current output.) For the bivariate system studied in this paper, the disturbance to investment share does not affect per capita output contemporaneously (i.e., $m_{0,12}=0$ in the notation of this paper, where $m_{0, i j}$ is the row- $i$, column- $j$ element of the leading VMA parameter matrix $M_{0}$ ); see Eq. (4) or Eq. (6). As a result, the use of Sims' (1980) recursive identification scheme (with per capita output ordered first) is valid when current output is 
determined in the supply side. ${ }^{8}$

Of course, no identifying assumption is appropriate in all circumstances or is consistent with all theoretical models. The above identification scheme is chosen as it reflects the maintained hypothesis that the data are generated by some growth models. Moreover, this choice is neutral with respect to the exogenous versus endogenous growth debate.

\subsection{A test of zero long-run effect and the underlying idea}

Under the assumption that a disturbance to productivity will always produce permanent effects, the analysis in Section 2 shows that $M_{12}(1)=0$ in Eq. (7) (which is equivalent to saying that the second column of $M(1)$ is zero, since $M_{12}(1)=M_{22}(1)$ in the above cointegrated system) for an exogenous growth model, but is positive for an endogenous growth model. Thus, the rejection of zero long-run effect of an investment share disturbance is a necessary (but not sufficient) condition for the cointegrated system (7) to be generated by an endogenous growth model. This sub-section shows that under the identifying assumption of $m_{0,12}=0$, there is a simple way to test the null hypothesis of $M_{12}(1)=0$. The test is based on the estimated coefficients of the following reduced-form bivariate vector error-correction system:

$$
\begin{aligned}
{\left[\begin{array}{c}
\Delta x_{1 t} \\
\Delta x_{2 t}
\end{array}\right] } & \equiv\left[\begin{array}{c}
\beta_{1}^{R} \\
\beta_{2}^{R}
\end{array}\right]+\sum_{j=1}^{p}\left(\begin{array}{cc}
\pi_{j, 11}^{R} & \pi_{j, 12}^{R} \\
\pi_{j, 21}^{R} & \pi_{j, 22}^{R}
\end{array}\right)\left[\begin{array}{l}
\Delta x_{1, t-j} \\
\Delta x_{2, t-j}
\end{array}\right] \\
+ & {\left[\begin{array}{c}
\lambda_{1}^{R} \\
\lambda_{2}^{R}
\end{array}\right]\left(x_{2, t-1}-x_{1, t-1}\right)+\left[\begin{array}{c}
\varepsilon_{1 t}^{R} \\
\varepsilon_{2 t}^{R}
\end{array}\right], }
\end{aligned}
$$

8 It should be emphasized that this recursive nature depends only on the assumption that current output is determined in the supply side, and therefore may be present in an optimizing model or in an exogenous investment share model. To make the analysis relatively simple and intuitive, Section 2 uses an exogenous investment share assumption, and thus the structural disturbance $\varepsilon^{I}$ in Eq. (2) is naturally interpreted as a disturbance to investment share. Alternatively, if the bivariate system of per capita output and per capita investment is generated by a more elaborate model (such as an optimizing model with government), then the structural disturbance $\varepsilon^{I}$ may be interpreted as a mixture of disturbances to government policy and the agent's utility function. For example, a negative disturbance to $\varepsilon^{I}$ in the bivariate framework of this paper may capture a positive disturbance to income tax revenue (the type of disturbances considered in Stokey and Rebelo, 1995). 
where $p$ is the lag length, and $\lambda^{R}=\left(\lambda_{1}^{R}, \lambda_{2}^{R}\right)^{\prime}$ is the reduced-form adjustment vector. Note that the components of $\varepsilon_{t}^{R}=\left(\varepsilon_{1 t}^{R}, \varepsilon_{2 t}^{R}\right)^{\prime}$ in this reduced-form system are serially uncorrelated (which is a reasonable assumption provided that there are enough lag terms) but may be contemporaneously correlated with each other.

Under the identifying assumption of $m_{0,12}=0$, it can be shown that testing whether $\lambda_{1}^{R}$, the first element of the adjustment vector of the reduced-form vector error-correction model (8), is zero or non-zero can be used to examine whether the long-run effect of a disturbance to investment share is zero $\left(M_{12}(1)=0\right)$ or not. ${ }^{9}$ More generally, the above result can be stated as:

Proposition 1 If the Sims' $x_{1}$-first ordering is adopted for the bivariate cointegrated system of variables $x_{1}$ and $x_{2}$, then testing whether $\lambda_{1}^{R}$ in Eq. (8) is zero or not can be used to examine whether the long-run effect of a structural $x_{2}$-disturbance is zero or not. By symmetry, if the Sims' $x_{2}$-first ordering is adopted, then testing whether $\lambda_{2}^{R}$ is zero or not can be used to examine whether the long-run effect of a $x_{1}$-disturbance is zero or not.

A brief discussion of the underlying idea of Proposition 1 is given as follows. There is an assumption regarding the statistical property of the data (that the two variables are cointegrated), and there is an identifying assumption regarding the structural disturbances (that there is no contemporaneous effect of a $x_{2}$-disturbance on the other variable $x_{1}$ ).

Since the rank of the long-run multiplier matrix for the structural VMA representation (7) of a bivariate cointegrated system is one, at least one column of the matrix must be non-zero. Through the relationships among various representations of a cointegrated system (see, for example, Engle and Granger, 1987, and Banerjee et al., 1993), it can be shown that the null hypothesis of $M_{12}(1)=0$ (which corresponds to a stochastic exogenous growth model in the context of the endogenous versus exogenous growth debate) implies that $\lambda_{1}$ is zero, where $\lambda_{1}$ is the coefficient of the error-correction term in the first equation of the following structural vector error-correction model corresponding to

9 In studying a bivariate system, it is implicitly assumed that the specification of only two structural disturbances is meaningful; see, for example, Cochrane (1994), Lastrapes and Selgin (1994), Quah and Vahey (1995) and, especially, Blanchard and Quah (1989). When the number of underlying disturbances is more than two, the proposed test in a bivariate cointegrated system to distinguish between the endogenous and exogenous growth models is still valid under the assumptions that (a) current output is determined in the supply side and (b) the 'other disturbance' $\left(\varepsilon^{I}\right)$, which captures all disturbances orthogonal to the output disturbance and is identified as having no contemporaneous effect on output, produces a zero long-run effect on output for an exogenous growth model. 
(8):

$$
\begin{gathered}
\Pi_{0}\left[\begin{array}{c}
\Delta x_{1 t} \\
\Delta x_{2 t}
\end{array}\right] \equiv\left[\begin{array}{ll}
\pi_{0,11} & \pi_{0,12} \\
\pi_{0,21} & \pi_{0,22}
\end{array}\right]\left[\begin{array}{c}
\Delta x_{1 t} \\
\Delta x_{2 t}
\end{array}\right]=\left[\begin{array}{c}
\beta_{1} \\
\beta_{2}
\end{array}\right] \\
+\sum_{j=1}^{p}\left[\begin{array}{ll}
\pi_{j, 11} & \pi_{j, 12} \\
\pi_{j, 21} & \pi_{j, 22}
\end{array}\right]\left[\begin{array}{l}
\Delta x_{1, t-j} \\
\Delta x_{2, t-j}
\end{array}\right]+\left[\begin{array}{c}
\lambda_{1} \\
\lambda_{2}
\end{array}\right]\left(x_{2, t-1}-x_{1, t-1}\right)+\left[\begin{array}{l}
\varepsilon_{1 t} \\
\varepsilon_{2 t}
\end{array}\right] .
\end{gathered}
$$

Finally, the relationship between the structural model (9) and the reducedform model (8) implies the following relationship [see, for example, Cochrane $(1994)]:{ }^{10}$

$$
\left[\begin{array}{c}
\lambda_{1} \\
\lambda_{2}
\end{array}\right] \equiv \lambda=\left(M_{0}\right)^{-1} \lambda^{R}=\frac{1}{\left|M_{0}\right|}\left[\begin{array}{l}
m_{0,22} \lambda_{1}^{R}-m_{0,12} \lambda_{2}^{R} \\
m_{0,21} \lambda_{1}^{R}-m_{0,11} \lambda_{2}^{R}
\end{array}\right]
$$

Combining with Eq. (10) and the identifying assumption of $m_{0,12}=0$, the hypothesis of $\lambda_{1}=0$ about the unobserved structural model has a testable implication of $\lambda_{1}^{R}=0$ about the reduced-form model.

\subsection{The empirical procedure}

The above results suggest the following procedure to examine the long-run effect of the investment share disturbance. The first step is to estimate the reduced-form vector error-correction model (8). Based on the estimated coefficients (as well as the estimated variance-covariance matrix), the next step is to test $\lambda_{1}^{R}=0$ and to obtain the long-run response of an investment share disturbance on per capita output, $M_{12}(1)$, under the identifying assumption $m_{0,12}=0 .{ }^{11}$ As mentioned above, the test of $\lambda_{1}^{R}=0$ is a test of the hypothesis

${ }^{10}$ Premultiplying the structural vector error-correction model (9) by $\left(\Pi_{0}\right)^{-1}$ and comparing it with its reduced-form counterpart (8) give Eq. (10) and $\varepsilon_{t}^{R}=$ $\left(\Pi_{0}\right)^{-1} \varepsilon_{t}=M_{0} \varepsilon_{t}$, where $M_{0}=\left(\Pi_{0}\right)^{-1}$ can be shown to hold. Moreover, the above relationship and the normalization of variances of the structural disturbances imply that the reduced-form variance-covariance matrix, $E\left(\varepsilon_{t}^{R} \varepsilon_{t}^{R \prime}\right)$, is related to $M_{0}$ according to $E\left(\varepsilon_{t}^{R} \varepsilon_{t}^{R \prime}\right)=M_{0} E\left(\varepsilon_{t} \varepsilon_{t}^{\prime}\right) M_{0}^{\prime}=M_{0} M_{0}^{\prime}$. For a bivariate system, this relationship gives three independent restrictions. With one more restriction, the four elements of $M_{0}$ can be recovered and thus the structural model is identified.

11 The long-run response can be obtained by standard methods for impulse-response function, which can be found in most statistical packages. Since the distinguishing feature between endogenous and exogenous growth models lie on the long-run response, the impulse responses at other lags are not presented in this paper. 
of zero long-run effect of a structural disturbance to investment share, under the identifying assumption $m_{0,12}=0$.

There are two possibilities. First, if either (a) the null hypothesis $\lambda_{1}^{R}=0$ is not rejected, or (b) the null hypothesis $\lambda_{1}^{R}=0$ is rejected but the estimated long-run response $M_{12}(1)$ is negative, then the evidence is more consistent with an exogenous growth model than an endogenous growth model. Second, if the null hypothesis $\lambda_{1}^{R}=0$ is rejected and the estimated long-run response of an investment share disturbance on per capita output, $M_{12}(1)$, is positive, then the evidence is more favorable to the endogenous growth model.

\section{Empirical analysis}

The empirical analysis focuses on the four major industrial countries (France, Japan, UK and USA) in the post World War II period. ${ }^{12}$ The data are taken from the Penn World Table version 6.1 (PWT6.1); a description of an earlier version 5 is given in Summers and Heston (1991). The per capita real GDP figures are the 'RGDPL' series, and the per capita real investment figures are obtained from combining the 'RGDPL' and 'KI' series (real gross domestic investment as percentage of real GDP). The various series for these four countries are plotted in Figures 1 to 4. All the (annual) series are from 1950 to 2000, and are measured in 1996 international prices. The post-war period is chosen primarily because of compatibility with previous studies on the effect of investment share on output, such as of Levine and Renelt (1992) and, especially, Jones (1995, Section III). The former study uses cross-country data from 1960 to 1989, and the latter uses annual series of industrial countries from 1950 to 1988 and mentions that the choice of that sample avoids changes in the stochastic properties associated with World War II (p. 501).

[Insert Figures 1 to 4 here.]

The maximum order of the vector error-correction model is assumed to be four. The Akaike Information Criterion (AIC), the Bayesian Information Criterion (BIC), and the Durbin-Watson statistics for the models with various lags are presented in Table 1. For France, the model with one lag term is chosen by both the AIC and BIC. For Japan, UK and USA, the model with two lag terms is chosen by the AIC and the model with one lag is chosen by the BIC. A comparison of the Durbin-Watson statistics suggest that the model with two lags is the more preferred choice for each of them. To conserve space, only

\footnotetext{
$\overline{12}$ In the PWT6.1 data set, the real GDP per worker series for Germany starts from 1990 and other variables start from 1970. As these series are too short for meaningful analysis, Germany is not examined in this paper.
} 
the results for the model with two lags are focused for these three countries, but the robustness of the conclusion with respect to the number of lag terms will be examined. The various regression equations run from 1955 to 2000, with the earlier observations used as starting values.

\section{[Insert Table 1 here.]}

The empirical procedure of this paper is developed for a bivariate cointegrated system. To test whether or not per capita output and per capita investment are cointegrated with a known cointegrating vector, this paper uses the test suggested in Horvath and Watson (1995), which has been shown to possess better power properties when compared to the augmented Dickey-Fuller tests. Moreover, this test fits nicely into Eq. (8). A test of the null hypothesis that log per capita output and log per capita investment are I(1) but not cointegrated corresponds to the test of $\lambda_{1}^{R}=\lambda_{2}^{R}=0$ in Eq. (8). To test this hypothesis, a likelihood ratio test is performed by calculating the log-likelihood of the unrestricted model (8), as well as the log-likelihood of the restricted model:

$$
\left[\begin{array}{c}
\Delta x_{1 t} \\
\Delta x_{2 t}
\end{array}\right] \equiv\left[\begin{array}{c}
\beta_{1}^{R} \\
\beta_{2}^{R}
\end{array}\right]+\sum_{j=1}^{p}\left(\begin{array}{cc}
\pi_{j, 11}^{R} & \pi_{j, 12}^{R} \\
\pi_{j, 21}^{R} & \pi_{j, 22}^{R}
\end{array}\right)\left[\begin{array}{c}
\Delta x_{1, t-j} \\
\Delta x_{2, t-j}
\end{array}\right]+\left[\begin{array}{c}
\varepsilon_{1 t}^{R} \\
\varepsilon_{2 t}^{R}
\end{array}\right] .
$$

The test statistic is given by:

$$
L R=2\left(\ln L_{u}-\ln L_{R}\right),
$$

where $\ln L_{u}$ is the log-likelihood of the unrestricted model (8) and $\ln L_{R}$ is the log-likelihood of the restricted model (11). The critical values of the test statistic are given in Table 1 of Horvath and Watson (1995).

The results of the cointegration test are presented in Table 2. It can be observed that the null hypothesis is rejected at $10 \%$ significance level for UK, at $1 \%$ significance level for France and Japan, but is not rejected at $10 \%$ significance level for USA. For France, Japan and UK, there is evidence that the $\log$ of investment-output ratio is $\mathrm{I}(0)$. As a result, the empirical procedure of this paper is applied to these three countries but not to USA; see footnote 7 as well.

[Insert Table 2 here.]

The regression results of the vector error-correction model (8) for France, Japan and UK, with the lag length in each country determined by AIC, are presented in Table 3. Based on the estimated coefficients and the identifying assumption that a disturbance to investment share does not affect current per capita output, the long-run responses of the level of per capita output to both structural disturbances can be obtained. They are also given in Table 3. 
According to Proposition 1, the coefficient of the error-correction term for the per capita output equation can be used to test whether the long-run effect of an investment share disturbance is zero or not if this disturbance does not affect per capita output contemporaneously. ${ }^{13}$ It is observed from Table 3 that the $t$-statistic of the estimated coefficient of the error-correction term of the per capita output equation is -0.95 for UK. Thus, the coefficient $\lambda_{1}^{R}$ is not statistically different from zero at a $5 \%$ significance level. On the other hand, the $t$-statistic of the estimated coefficient of the error-correction term of the per capita output equation is -2.79 for France and -3.42 for Japan, but the estimated long-run response, $M_{12}(1)$, is negative in each case (-0.014 for France and -0.035 for Japan). Thus, the null hypothesis that the data are generated by an exogenous growth model is not rejected by the post-war data of France, Japan and UK.

A practical virtue of the simple statistical procedure (OLS regression) used in the above analysis is that the results are quite robust with respect to the number of lag terms included. First of all, if the number of lag terms is chosen by the BIC, then the likelihood ratio statistics of the Horvath and Watson (1995) test are given in the upper panel of Table 4. It can be seen that the null hypothesis that the log of investment share is $\mathrm{I}(0)$ can be rejected at a $1 \%$ significance level for Japan and at a $5 \%$ significance level for UK, but is not rejected at a $10 \%$ significance level for USA. These conclusions are essentially the same whether the number of lag terms are determined by the AIC or BIC.

[Insert Table 4 here.]

The estimated coefficients and the $t$-statistics for the error-correction terms, and the long-run responses of the structural disturbances (under the recursive ordering with per capita output first) for each country with various lags are presented in the upper panel of Table 5 . It can be observed that the estimated coefficients of the error-correction terms and the associated $t$-statistics for the

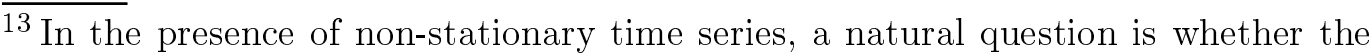
distributions of the various test statistics (especially those of the error-correction coefficients) are standard or not under the null hypothesis. The results in Sims et al. (1990) make clear that under the maintained assumption that the variables are cointegrated, the $t$-statistic for the null hypothesis follows standard distribution asymptotically because all the right-hand side variables of the regressions are $\mathrm{I}(0)$. Note that the test $\lambda_{1}^{R}=0$ is a test of zero long-run effect under the maintained assumption of cointegration, and is neither a unit root nor cointegration test. On the other hand, the asymptotic distribution of the null hypothesis $\lambda_{1}^{R}=\lambda_{2}^{R}=0$ (i.e., the null hypothesis of no cointegration) is non-standard; see Table 2.
} 
models with different lags remain relatively unchanged in each country. ${ }^{14}$ For the various models with one to four lags in either France, Japan or UK, it is still concluded that a disturbance to investment share does not have a positive long-run effect on per capita output.

\section{[Insert Table 5 here.]}

In the theoretical models in Section 2, the simplifying assumption of inelastic labor supply is used, as in most growth models. In empirical papers examining the relevance of theoretical growth models, researchers have used either the data based on total population or total number of workers. To see whether the above conclusion is robust with respect to the choice of variables, this paper also uses the real GDP per worker series ('RGDPWOK' series in PWT61) and the real investment per worker series (by combining the 'RGDPWOK' and 'KI' series).

In the lower panel of Table 4, the likelihood ratio statistics are presented. It can be observed that the null hypothesis that log output per worker and log investment per worker are I(1) but not cointegrated is rejected at a $10 \%$ significance level for UK, at a 5\% significance level for France and at a $1 \%$ significance level for Japan, but is not rejected at a $10 \%$ significance level for USA.

In the lower panel of Table 5 , it is observed that the $t$-statistic of the estimated coefficient of the error-correction term of the output per worker equation is -1.21 for UK. Thus, the coefficient $\lambda_{1}^{R}$ is not statistically different from zero at a $5 \%$ significance level. On the other hand, the $t$-statistic of the estimated coefficient of the error-correction term of the output per worker equation is -3.17 for France and -3.52 for Japan, but the estimated long-run response, $M_{12}(1)$, is negative in each case (-0.022 for France and -0.036 for Japan). Thus, the null hypothesis that the data are generated by an exogenous growth model is not rejected by the post-war data of France, Japan and UK.

To summarize, when per capita output and per capita investment are cointegrated and the Sims' output-first ordering is valid, the test of $\lambda_{1}^{R}=0$ in Eq. (8) and the long-run response of an investment share disturbance on output can be used to examine whether a disturbance to investment share produces a zero or positive effect on per capita output. For France, Japan and UK, it is concluded that a temporary change in investment share does not produce a positive long-run effect on per capita output. The evidence is more consistent with the class of exogenous growth models than with the class of endogenous growth models. This conclusion holds whether per capita series or per worker

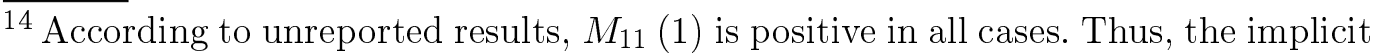
assumption that the productivity disturbance produces positive long-run effects is satisfied.
} 
series are used, and is also robust to the number of lag terms included.

\section{Conclusion}

A major empirical interest, and a distinguishing characteristic between endogenous and exogenous growth models, is whether a permanent change in investment share produces a growth effect or only a level effect. Unfortunately, a direct time series analysis of this hypothesis may not always be possible due to a lack of permanent changes in investment share. In fact, for most countries such as France, Japan and UK, investment-output ratios fluctuate around a constant mean and there is no evidence of a permanent change in this variable; see the discussion in King et al. (1991) and Cochrane (1994), as well as Figures 1 to 3 of this paper. To prevent determining the empirical relevance of the endogenous growth models by examining the long-run effects of a (possibly non-existent) permanent change in investment share, this paper takes a complementary approach. It assumes that such a permanent change is absent (or at least cannot be established affirmatively) in the data, and considers the long-run effect of a temporary change in investment share.

The first contribution (Section 2) of this paper is to relate the apparently distinct questions of the long-run effect of a permanent change in economic fundamentals (as examined in Jones, 1995; Stokey and Rebelo, 1995) and that of a temporary change (as examined in Kocherlakota and Yi (1996) and this paper). It then suggests that when per capita output and per capita investment are cointegrated, testing the long-run effect of a temporary change in investment share on per capita output provides an indirect answer regarding the growth versus level effect debate.

The second contribution (Section 3) of the paper is to develop a method to examine whether the long-run effect of a disturbance to investment share on per capita output is zero or positive. Using the systematic difference in time series properties of endogenous and exogenous growth models (in Section 2) and the relationships of different representations of a cointegrated system (in Section 3 ), this paper suggests a simple test of zero long-run effect of a disturbance to investment share. Specifically, under the assumption that an investment share disturbance does not affect per capita output contemporaneously (which is consistent with the idea commonly found in the growth literature that current output is determined in the supply side), Proposition 1 shows that the coefficient of the error-correction term for the per capita output equation in model (8) can be used to test whether the long-run effect of a temporary change in investment share is significantly different from zero.

The empirical framework of this paper shares some similarities with Kocher- 
lakota and Yi (1996), as the long-run effects of temporary changes in economic fundamentals are examined in both papers. However, there are also a number of differences between the two papers. Kocherlakota and Yi (1996) focus on a set of policy variables for USA, while investment shares of several industrial countries are examined in this paper. Kocherlakota and Yi (1996, p. 127) provide statistical justifications for the three cases in which their methods are appropriate, whereas this paper combines economic analysis and time series properties of the data to suggest a method to distinguish between endogenous and exogenous growth models when per capita output and per capita investment are cointegrated. Finally, Kocherlakota and Yi (1996) use a singleequation approach, but this paper uses a system approach. ${ }^{15}$

The third contribution (Section 4) of this paper is about empirical evidence. Applying the method to France, Japan and the UK, it is found that a disturbance to investment share does not have a positive long-run effect on per capita output. These results are quite robust with respect to lag length and to the choice of variables. Even though this paper assumes that the investmentoutput ratio is stationary and therefore does not share with a major premise in Jones (1995) regarding the presence of deterministic or stochastic trend in this ratio, the conclusions obtained in these two papers are similarly unfavorable to endogenous growth models. ${ }^{16}$ Moreover, they are complementary in the sense that no positive growth effect associated with a permanent change in investment share is found in one study and no positive permanent level effect associated with a temporary change in investment share is found in the other. The time series evidence appears to be quite different from the positive and significant relationship between investment share and output growth found in cross-section studies.

With the focus on examining whether the long-run effect of a temporary change in investment share on per capita output is zero or positive, the ob-

15 While only $\lambda_{1}^{R}$ of the per capita output equation is required to test the null
hypothesis of zero long-run effect of an investment share disturbance under the as-
sumption that an investment share disturbance does not affect per capita output
contemporaneously (and therefore, the Sims' $X_{1}$-first ordering is valid), both equa-
tions of (8) are required to estimated the long-run response $M_{12}(1)$. Moreover, the
evidence based on both equations is useful in determining the lag length according
to the AIC or BIC.
${ }^{16}$ The conclusions of these two papers using time series analysis are not necessarily
inconsistent with the evidence of Kocherlakota and Yi (1996) - another time series
study which, however, does not examine the relationship between investment share
and output growth - even though they have found some evidence in favor of endoge-
nous growth models. They examine US data starting from 1910 s for taxes, tariffs,
money growth rate, government equipment and structural capital (both military
and non-military) and find robust evidence supporting endogenous growth models
based on government non-military structural capital but not the other six variables. 
jectives of this paper are to derive testable implications of some theoretical growth models and then to perform empirical analysis for post-war data of the major industrial countries. Other interesting questions are not investigated in this paper and left to future research. One possible extension is to examine the above hypothesis by combining the information of France, Japan and UK (and possibly other industrial countries as well, provided that the stationarity assumption for investment share is reasonable). While this could simply be done by testing the joint hypothesis that the coefficients of the error-correction terms for the per capita output equations in all three countries are zero, it may be better to first derive and then test the implications of theoretical growth models allowing for capital and/or labor mobility. It is interesting to see whether the empirical evidence based on testing the implications of growth models with factor mobility is consistent with those examining growth models in which each economy is implicitly assumed to evolve independently of others. Another, and a more ambitious, task would be to reconcile the different methodologies and conclusions used in cross-section studies (such as Barro, 1991; Mankiw et al., 1992; Levine and Renelt, 1992) and time series studies (such as Jones (1995) and this paper) regarding the relationship between investment share and per capita output growth. This investigation would potentially parallel the interesting work of Bernard and Durlauf (1996) which provides a unified framework for interpreting the diverse definitions, methods and results of cross-section and time series tests of the convergence hypothesis.

\section{References}

[1] Barro, R. J. (1991), "Economic growth in a cross section of countries," Quarterly Journal of Economics 106:407-443.

[2] Banerjee, A., J. Dolado, J. W. Galbraith and D. F. Hendry (1993), Cointegration, and the Econometric Analysis of Non-stationary Data. Oxford University Press.

[3] Bernard, A. B. and S. N. Durlauf (1996), "Interpreting tests of the convergence hypothesis," Journal of Econometrics 71:161-173.

[4] Blanchard, O. J. and D. Quah (1989), "The dynamic effects of aggregate supply and demand disturbances," American Economic Review 79:655-673.

[5] Cochrane, J. H. (1994), "Permanent and transitory components of GNP and stock prices," Quarterly Journal of Economics 109:241-265.

[6] Collard, F. (1999), "Spectral and persistence properties of cyclical growth," Journal of Economic Dynamics and Control 23:463-488.

[7] Engle, R. F. and C. W. J. Granger (1987), "Co-integration and error correction: Representation, estimation, and testing," Econometrica 55:251-276. 
[8] Glomm, G. and B. Ravikumar (1994), "Public Investment in Infrastructure in a Simple Growth Model," Journal of Economic Dynamics and Control 18:11731187.

[9] Horvath, M. T. K. and M. W. Watson (1995), "Testing for cointegration when some of the cointegrating vectors are prespecified," Econometric Theory 11:9841014.

[10] Jones, C. J. (1995), "Time series tests of endogenous growth models," Quarterly Journal of Economics 110:495-525.

[11] King, R. G., C. I. Plosser, J. H. Stock and M. W. Watson (1991), "Stochastic trends and economic fluctuations," American Economic Review 81:819-840.

[12] Kocherlakota, N. R. and K. Yi (1996), "A simple time series test of endogenous vs. exogenous growth models: An application to the United States," Review of Economics and Statistics 78:126-134.

[13] Lastrapes, W. D. and G. Selgin (1994), "Buffer-stock money: Interpreting short-run dynamics using long-run restrictions," Journal of Money, Credit and Banking 26:34-54.

[14] Lau, S.-H. P. (1997), "Using stochastic growth models to understand unit roots and breaking trends," Journal of Economic Dynamics and Control 21:16451667.

[15] Lau, S.-H. P. (1999), "I(0) in, integration and cointegration out: Time series properties of endogenous growth Models," Journal of Econometrics 93:1-24.

[16] Levine, R. and D. Renelt (1992), "A sensitivity analysis of cross-country growth regressions," American Economic Review 82:942-963.

[17] Lucas, R. E., Jr. (1988), "On the mechanics of economic development," Journal of Monetary Economics 22:3-42.

[18] Mankiw, N. G. (1997), Macroeconomics, Third Edition. New York: Worth Publishers.

[19] Mankiw, N. Gregory, D. Romer and D. N. Weil (1992), "A contribution to the empirics of economic growth," Quarterly Journal of Economics 107:407-437.

[20] Quah, D. and S. P. Vahey (1995), "Measuring core inflation," Economic Journal 105:1130-1144.

[21] Rebelo, S. (1991), "Long-run policy analysis and long-run growth," Journal of Political Economy 99:500-521.

[22] Romer, P. M. (1986), "Increasing returns and long-run growth," Journal of Political Economy 94:1002-1037.

[23] Sims, C. A. (1980), "Macroeconomics and reality," Econometrica 47:1-48.

[24] Sims, C. A., J. H. Stock and M. W. Watson (1990), "Inference in linear time series models with some unit roots," Econometrica 58:113-144. 
[25] Solow, R. M. (1956), "A contribution to the theory of economic growth," Quarterly Journal of Economics 70:65-94.

[26] Stokey, N. L. and S. Rebelo (1995), "Growth effects of flat-rate taxes," Journal of Political Economy 103:519-550.

[27] Summers, R. and A. Heston (1991), "The Penn World Table (Mark 5): An expanded set of international comparisons, 1950-1988," Quarterly Journal of Economics 106:327-368.

[28] Swan, T. W. (1956), "Economic growth and capital accumulation," Economic Record 32:334-361. 
Figure 1: France

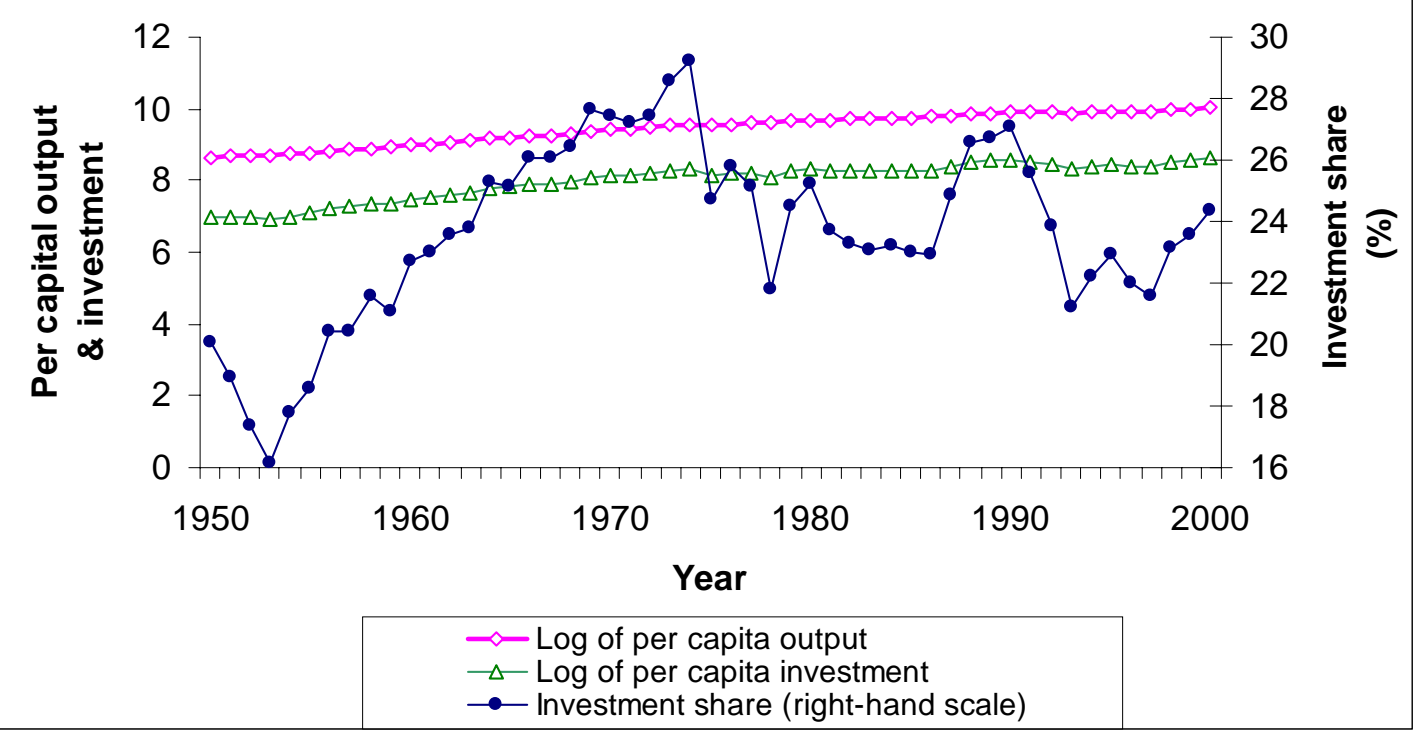

Figure 2: Japan

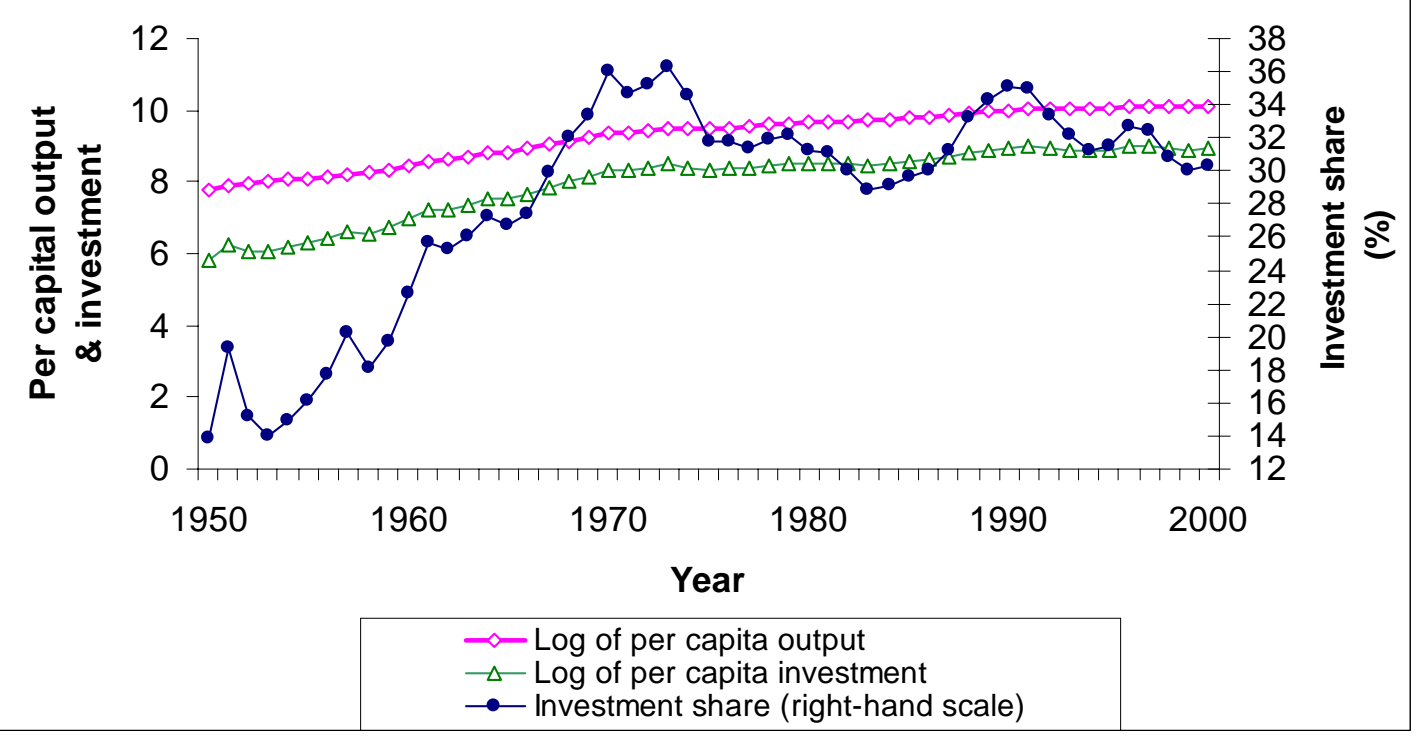




\section{Figure 3: UK}

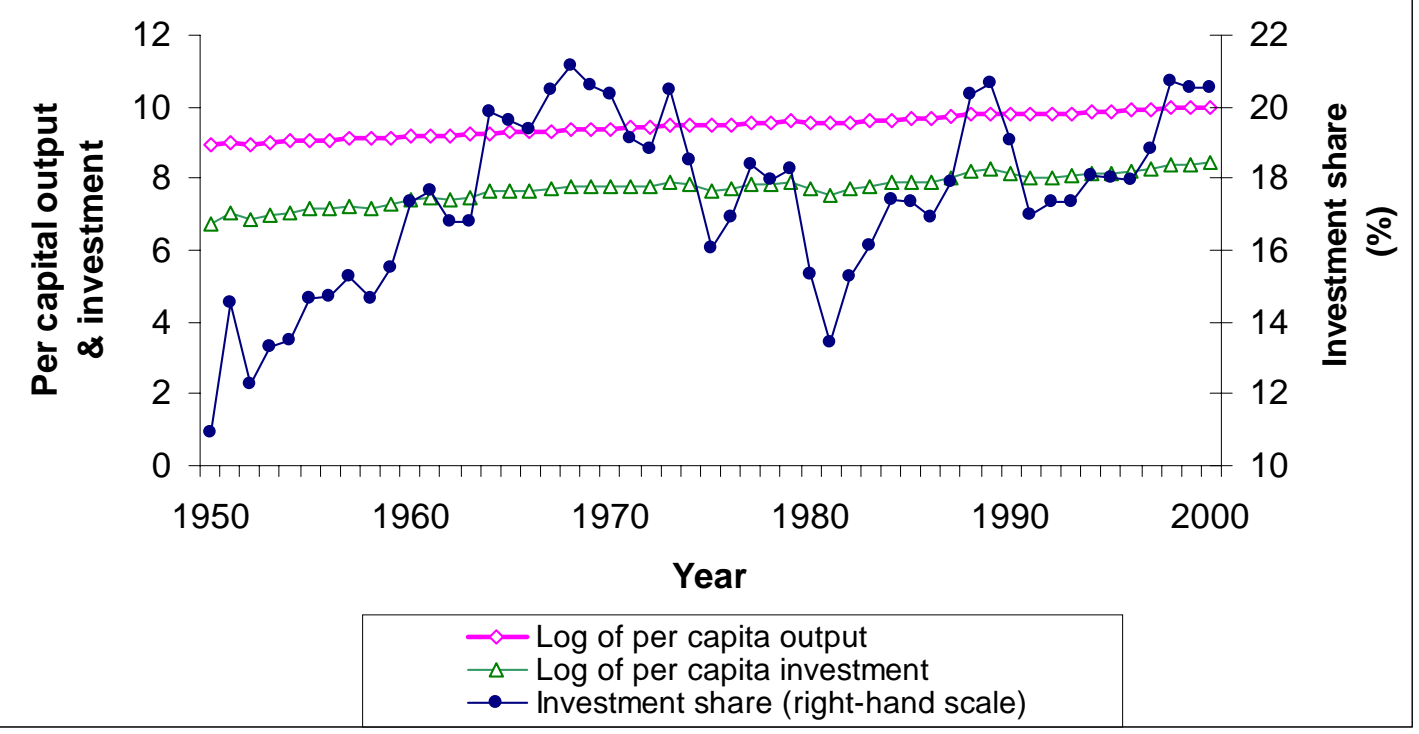

Figure 4: USA

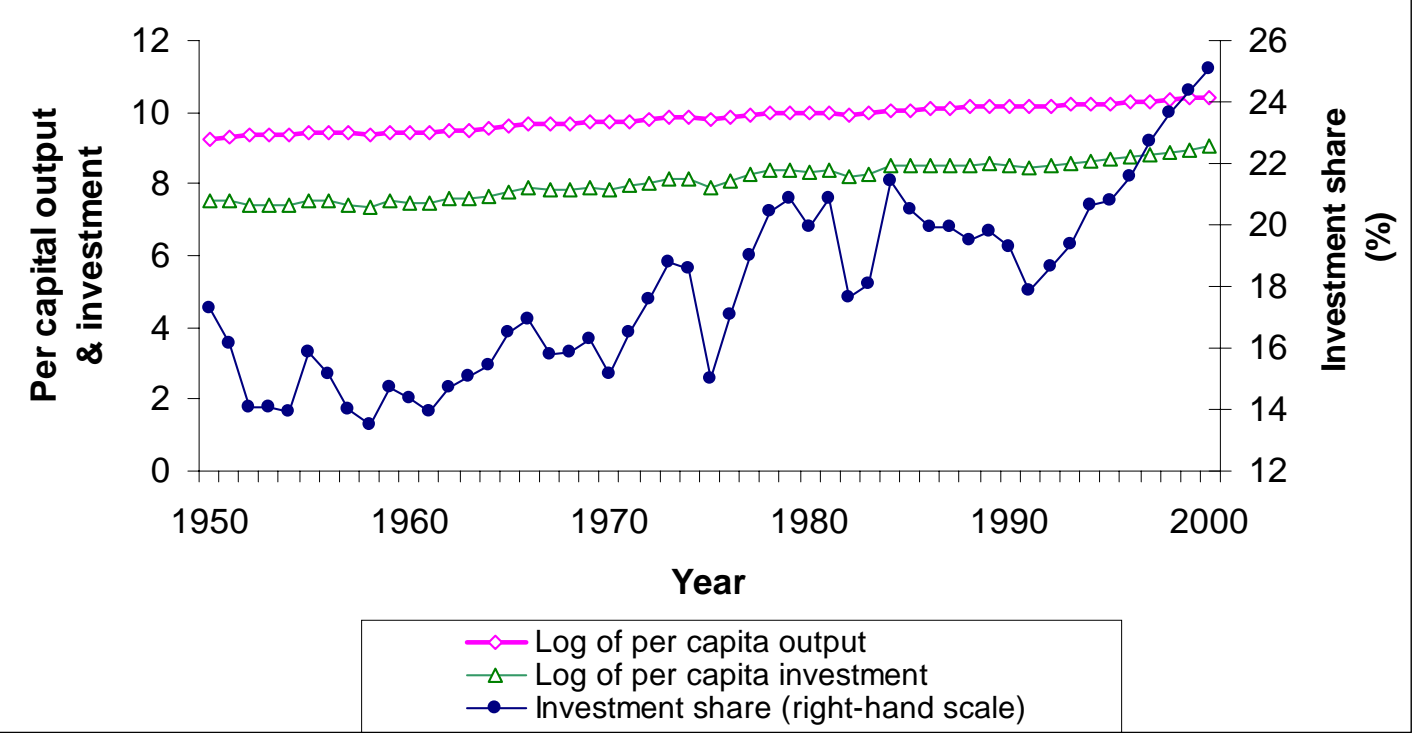


Table 1:

AIC, BIC and Durbin-Watson Statistics

\begin{tabular}{|c|c|cccc|}
\hline Country & Lag length & AIC & BIC & DW $(\Delta l y)$ & DW $(\Delta l i)$ \\
\hline France & 1 & -9.05 & -8.73 & 1.95 & 1.97 \\
France & 2 & -8.92 & -8.45 & 1.94 & 1.95 \\
France & 3 & -8.86 & -8.22 & 2.15 & 2.00 \\
France & 4 & -8.89 & -8.10 & 2.03 & 2.01 \\
Japan & 1 & -8.44 & -8.13 & 2.37 & 2.03 \\
Japan & 2 & -8.54 & -8.06 & 2.11 & 2.09 \\
Japan & 3 & -8.47 & -7.83 & 2.12 & 2.08 \\
Japan & 4 & -8.38 & -7.58 & 2.16 & 2.08 \\
UK & 1 & -8.49 & -8.17 & 1.76 & 1.69 \\
UK & 2 & -8.56 & -8.09 & 2.03 & 1.94 \\
UK & 3 & -8.42 & -7.78 & 1.98 & 1.92 \\
UK & 4 & -8.42 & -7.63 & 2.01 & 1.98 \\
USA & 1 & -8.23 & -7.91 & 1.76 & 1.87 \\
USA & 2 & -8.26 & -7.79 & 1.82 & 1.91 \\
USA & 3 & -8.18 & -7.55 & 1.79 & 1.87 \\
USA & 4 & -8.12 & -7.32 & 1.77 & 1.81 \\
\hline
\end{tabular}

Note: AIC represents Akaike Information Criterion, BIC represents Bayesian Information Criterion, DW represents the Durbin-Watson statistic, and ly and li represent log per capita GDP and log per capita investment respectively. 
Table 2:

Likelihood Ratio Tests for the Null Hypothesis of No Cointegration

\begin{tabular}{|l|c|c|c|c|}
\hline Country & Lag length & $L_{U}$ & $L_{R}$ & $L R=2\left(L_{U}-L_{R}\right)$ \\
\hline France & 1 & 216.1 & 208.3 & $15.6^{* * * *}$ \\
\hline Japan & 2 & 208.3 & 199.5 & $17.6^{\text {**** }}$ \\
\hline UK & 2 & 208.9 & 204.4 & $9.0^{*}$ \\
\hline USA & 2 & 202.0 & 201.8 & 0.4 \\
\hline
\end{tabular}

Note: The number of lags is determined by the Akaike Information Criterion. $L R$ stands for the likelihood ratio test statistic for the hypothesis $\lambda_{1}=\lambda_{2}=0$ in Eq. (8). The critical value of the $L R$ test statistic for the null hypothesis of no cointegration is 8.30 at $10 \%$ significance level, 10.18 at 5\% significance level, and 13.73 at $1 \%$ significance level respectively (Horvath and Watson, 1995, Table 1). The symbols ${ }^{*},{ }^{* *}$ and ${ }^{* * *}$ represent statistical significance at $10 \%, 5 \%$, and $1 \%$ respectively. 
Table 3:

Estimated Coefficients and $t$-statistics for France, Japan and UK, 1955-2000

\begin{tabular}{|c|c|c|c|c|c|c|c|}
\hline \multirow{2}{*}{\multicolumn{2}{|c|}{\begin{tabular}{|c|} 
Country \\
Left-hand variable
\end{tabular}}} & \multicolumn{2}{|c|}{ France } & \multicolumn{2}{|c|}{ Japan } & \multicolumn{2}{|c|}{ UK } \\
\hline & & $\Delta l y_{t}$ & $\Delta l i_{t}$ & $\Delta l y_{t}$ & $\Delta l i_{t}$ & $\Delta l y_{t}$ & $\Delta l i_{t}$ \\
\hline \multirow{6}{*}{$\begin{array}{l}\text { Right-hand } \\
\text { variables }\end{array}$} & constant & $\begin{array}{c}-0.09 \\
(-2.43)\end{array}$ & $\begin{array}{c}-0.54 \\
(-3.98)\end{array}$ & $\begin{array}{c}-0.07 \\
(-3.03)\end{array}$ & $\begin{array}{c}-0.25 \\
(-4.28)\end{array}$ & $\begin{array}{c}-0.02 \\
(-0.44) \\
\end{array}$ & $\begin{array}{c}-0.38 \\
(-2.08) \\
\end{array}$ \\
\hline & $(l i-l y)_{t-1}$ & $\begin{array}{l}-0.068 \\
(-2.79)\end{array}$ & $\begin{array}{c}-0.36 \\
(-4.02)\end{array}$ & $\begin{array}{l}-0.056 \\
(-3.42)\end{array}$ & $\begin{array}{c}-0.19 \\
(-4.31)\end{array}$ & $\begin{array}{l}-0.023 \\
(-0.95)\end{array}$ & $\begin{array}{c}-0.24 \\
(-2.34) \\
\end{array}$ \\
\hline & $\Delta l y_{t-1}$ & $\begin{array}{c}0.93 \\
(4.01)\end{array}$ & $\begin{array}{c}2.82 \\
(3.33)\end{array}$ & $\begin{array}{c}0.87 \\
(3.54)\end{array}$ & $\begin{array}{c}2.21 \\
(3.38)\end{array}$ & $\begin{array}{c}0.49 \\
(1.83)\end{array}$ & $\begin{array}{c}2.19 \\
(1.93)\end{array}$ \\
\hline & $\Delta l y_{t-2}$ & & & $\begin{array}{c}0.44 \\
(1.90)\end{array}$ & $\begin{array}{c}0.46 \\
(0.76)\end{array}$ & $\begin{array}{c}-0.46 \\
(-1.73) \\
\end{array}$ & $\begin{array}{c}-2.07 \\
(-1.84) \\
\end{array}$ \\
\hline & $\Delta l i_{t-1}$ & $\begin{array}{c}-0.15 \\
(-2.44) \\
\end{array}$ & $\begin{array}{c}-0.53 \\
(-2.36) \\
\end{array}$ & $\begin{array}{c}-0.16 \\
(-1.75) \\
\end{array}$ & $\begin{array}{c}-0.42 \\
(-1.76) \\
\end{array}$ & $\begin{array}{c}-0.02 \\
(-0.38) \\
\end{array}$ & $\begin{array}{c}-0.06 \\
(-0.26) \\
\end{array}$ \\
\hline & $\Delta l i_{t-2}$ & & & $\begin{array}{c}-0.14 \\
(-1.75) \\
\end{array}$ & $\begin{array}{c}-0.35 \\
(-1.61) \\
\end{array}$ & $\begin{array}{c}0.03 \\
(0.53) \\
\end{array}$ & $\begin{array}{c}0.03 \\
(0.12) \\
\end{array}$ \\
\hline \multicolumn{2}{|c|}{$M_{11}(1)$} & \multicolumn{2}{|c|}{0.015} & \multicolumn{2}{|c|}{0.027} & \multicolumn{2}{|c|}{0.012} \\
\hline \multicolumn{2}{|c|}{$M_{12}(1)$} & \multicolumn{2}{|c|}{-0.014} & \multicolumn{2}{|c|}{-0.035} & \multicolumn{2}{|c|}{-0.004} \\
\hline
\end{tabular}

Note: Numbers without parentheses are the estimated coefficients and numbers inside parentheses represent $t$-statistics. 
Table 4: Cointegration Tests for Various Models

(A) Based on per capita output and per capita investment

\begin{tabular}{|l|c|c|c|c|}
\hline Country & Lag length & $L_{U}$ & $L_{R}$ & $L R=2\left(L_{U}-L_{R}\right)$ \\
\hline Japan & 1 & 202.2 & 194.4 & $15.6^{* * * *}$ \\
\hline UK & 1 & 203.2 & 197.0 & $12.4^{* * *}$ \\
\hline USA & 1 & 197.3 & 196.7 & 1.2 \\
\hline
\end{tabular}

(B) Based on output per worker and investment per worker

\begin{tabular}{|l|c|c|c|c|}
\hline Country & Lag length & $L_{U}$ & $L_{R}$ & $L R=2\left(L_{U}-L_{R}\right)$ \\
\hline France & 1 & 216.2 & 209.9 & $12.6^{* * *}$ \\
\hline Japan & 2 & 209.4 & 200.4 & $18.0^{* * * *}$ \\
\hline UK & 2 & 209.6 & 205.0 & $9.2^{*}$ \\
\hline USA & 2 & 198.2 & 197.7 & 1.0 \\
\hline
\end{tabular}

Note: See Table 2. 
Table 5:

Estimated Coefficients and Long-run Responses for Various Models

(A) Based on per capita output and per capita investment

\begin{tabular}{|c|c|ccc|}
\hline Country & Lag length & $\lambda_{1}^{R}$ & $\lambda_{2}^{R}$ & $M_{12}(1)$ \\
\hline France & 1 & $-0.068(-2.79)$ & $-0.36(-4.02)$ & -0.014 \\
\hline France & 2 & $-0.070(-2.64)$ & $-0.36(-3.70)$ & -0.014 \\
\hline France & 3 & $-0.072(-2.76)$ & $-0.36(-3.76)$ & -0.018 \\
\hline France & 4 & $-0.072(-2.71)$ & $-0.36(-3.60)$ & -0.028 \\
\hline Japan & 1 & $-0.052(-3.17)$ & $-0.18(-4.11)$ & -0.029 \\
\hline Japan & 2 & $-0.056(-3.42)$ & $-0.19(-4.31)$ & -0.035 \\
\hline Japan & 3 & $-0.060(-3.51)$ & $-0.20(-4.41)$ & -0.029 \\
\hline Japan & 4 & $-0.066(-3.76)$ & $-0.21(-4.59)$ & -0.029 \\
\hline UK & 1 & $-0.037(-1.54)$ & $-0.32(-3.03)$ & -0.007 \\
\hline UK & 2 & $-0.023(-0.95)$ & $-0.24(-2.34)$ & -0.004 \\
\hline UK & 3 & $-0.019(-0.75)$ & $-0.23(-2.19)$ & -0.003 \\
\hline UK & 4 & $-0.012(-0.45)$ & $-0.23(-2.11)$ & -0.001 \\
\hline
\end{tabular}

(B) Based on output per worker and investment per worker

\begin{tabular}{|l|c|ccc|}
\hline Country & Lag length & $\lambda_{1}^{R}$ & $\lambda_{2}^{R}$ & $M_{12}(1)$ \\
\hline France & 1 & $-0.076(-3.17)$ & $-0.32(-3.62)$ & -0.022 \\
\hline Japan & 2 & $-0.060(-3.52)$ & $-0.20(-4.35)$ & -0.036 \\
\hline UK & 2 & $-0.031(-1.21)$ & $-0.25(-2.40)$ & -0.005 \\
\hline
\end{tabular}

Note: Numbers before parentheses are the estimated coefficients and numbers inside parentheses are $t$-statistics. The long-run responses $M_{12}(1)$ are obtained under the identifying assumption of $m_{0,12}=0$. 